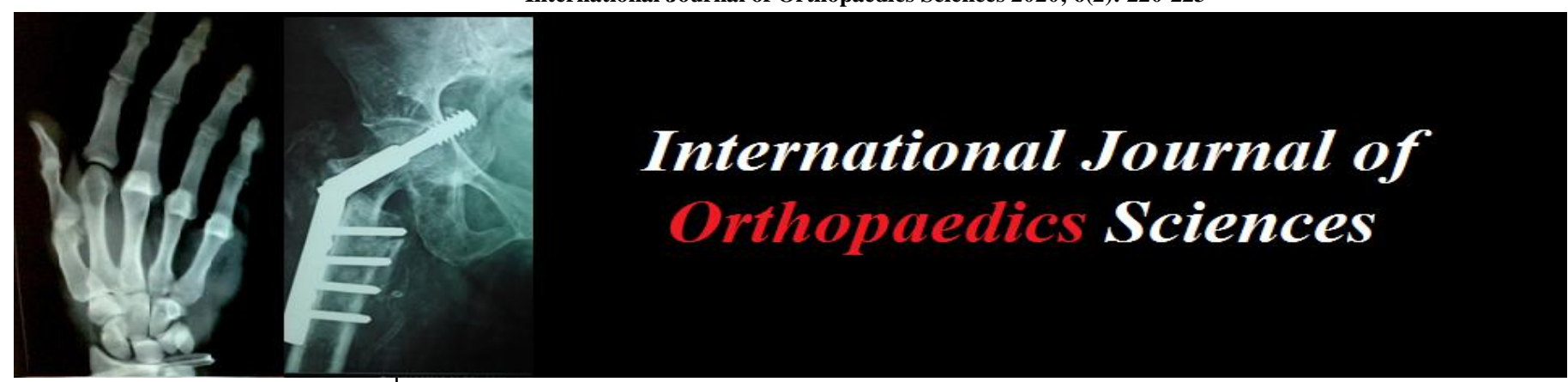

E-ISSN: 2395-1958

P-ISSN: 2706-6630

IJOS 2020; 6(2): 220-223

(C) 2020 IJOS

www.orthopaper.com

Received: 10-01-2020

Accepted: 14-02-2020

Hameed K Shaalan

Al-Najaf Health Directorate/

Training and human

development Center, Najaf-Iraq

Ghassan A Hussain

Medical City Complex, Baghdad, Iraq

Khalid Jasim Daham

Al-Hakim General

Hospital/Baghdad-Iraq
Corresponding Author: Hameed K Shaalan

Al-Najaf Health Directorate/

Training Health Center,

Baghdad-Iraq

\section{Uses of infliximab infusion in treatment of ankylosing spondylitis in Iraqi patients}

\author{
Hameed K Shaalan, Ghassan A Hussain and Khalid Jasim Daham
}

DOI: https://doi.org/10.22271/ortho.2020.v6.i2d.2042

\section{Abstract}

Ankylosing spondylitis refers to the inflammatory disorder associated with fibrous or bony bridging of joints in the spine, including the bridging of intervertebral discs. Objective: To assess the effect Infliximab Infusion and its Relation on Disease Activity, Severity and Acute Phase Reactant Protein in Iraqi Patients with Ankylosing Spondylitis. Patients and method: Ninty (90) patients were included in this study, were diagnosed as established AS patients who were attending the rheumatology outpatient clinic of Baghdad teaching hospital, thirty (45) patients of them were on conventional treatment (steroid and/or cytotoxic drugs), while the other thirty (45) patients were on biological treatment (infliximab infusion). Mean serum level of matrix metalloproteinase- 3 was statistically higher in patient group (4.42 $\pm 3.05 \mathrm{ng} / \mathrm{ml})$ than control group $(2.69 \pm 2.57 \mathrm{ng} / \mathrm{ml})$, and also was statistically higher in patients on conventional treatment $(5.31 \pm 3.16 \mathrm{ng} / \mathrm{ml})$ than those on biological treatment $(3.54 \pm 2.70 \mathrm{ng} / \mathrm{ml})$. The study shown that matrix metalloproteinase- 3 was higher in patient group than control group and also was higher in patients on conventional treatment than in patients on biological treatment.

Keywords: Ankylosing spondylitis, BASDAI, BASFAI, hs-CRP

\section{Introduction}

The name "ankylosing spondylitis" is derived from the Greek root "ankylosis," meaning stiffening of a joint, and "spondylos," which refers to a vertebra. "Ankylosing spondylitis" thus refers to the inflammatory disorder associated with fibrous or bony bridging of joints in the spine, including the bridging of intervertebral discs ${ }^{[1]}$.

The immunopathogenesis of AS is suspected to involve up regulation of proinflammatory cytokines. The dramatic response of AS patients to TNF blocking agent indicate that there is important contribution of TNF- $\alpha$ in the pathogenesis of AS ${ }^{[2]}$.

Nonsteroidal antiinflammatory drugs should be the first line of treatment for all symptomatic ankylosing spondylitis (AS) patients, unless contraindicated. In many patients, NSAIDs are the only medications required. About 70 to 80 percent of AS patients report substantial relief of their symptoms, including back pain and stiffness, with NSAIDs ${ }^{[3]}$.

Significant benefit has been noted in patients with axial as well as peripheral spondyloarthritis using the chimeric mouse-human monoclonal anti-TNF alpha antibody infliximab. Infliximab use also resulted in improvement in the synovial histopathology. Decreases in vascularity, thickness of the lining layer, and the degree of infiltration of synovium by neutrophils, macrophages, and $\mathrm{T}$ cells were seen ${ }^{[4]}$.

Bath Ankylosing Spondylitis Disease Activity Index (BASDAI) and Bath Ankylosing Spondylitis Functional Index (BASFI) questionnaires are widely used to evaluate disease activity and physical function, respectively, in patients with AS, and both are often applied in medical and clinical researches ${ }^{[5]}$.

C-Reactive Protein (CRP) is a blood protein that measures inflammation or infection. This marker reflects systemic inflammation in chronic disorders including Rheumatoid Arthritis, Psoriatic Arthritis, Crohn's Disease, Ulcerative Colitis, Ankylosing Spondylitis and other chronic health conditions ${ }^{[6]}$

Aim of the study: To assess the Infliximab Infusion and its Relation on Disease Activity, Severity and Acute Phase Reactant Protein in Iraqi Patients with Ankylosing Spondylitis. 


\section{Materials and Methods}

Kits and reagents: High Sensitivity C- Reactive Protein Nephelometry kit (Genrui Biotech Inc., China), ESR Pipette Set (LP ITALIANA SPA, Italy).

Patients: Sixty patients (75 males and 15 females) were attended to medical city, Baghdad teaching hospital, Department of Rheumatology outpatient clinic and biological therapy unit included in this study during period from beginning of October 2018 till end of October 2019, their mean age \pm Standard deviation $(S D)$ was $(43.15 \pm 9.7)$, (45) patients of them treated with biological agent (intravenous infusion of Infliximab of $5 \mathrm{mg} / \mathrm{kg}$ ), and other thirty (45) patients treated with conventional treatment (steroid and/or cytotoxic drugs).

Methods: From each individual three (3) ml of venous blood was aspirated, two milliliters ( $2 \mathrm{ml})$ of sample was put in ethylenediaminetetraacetic (EDTA) tubes for ESR testing and other (1) ml let clot at room temperature, then centrifuged to separate the serum which was collected in aliquots to store in $\left(-20^{\circ} \mathrm{C}\right)$ until needed for investigation of hs- CRP.

Statistical analysis: statistical analysis in this study was done using SPSS version computer software 20. T test was used to analyze the data and calculation of mean difference, Fisher exact and Chi-square test for comparison of proportion, $\mathrm{P}$ value of less than 0.05 was considered as statistically significant, $\mathrm{P}$-value $<0.01$ as highly significant and $\mathrm{P}$-value $<$ 0.001 as extremely significant.

Results This study was included sixty (90) patients with AS, fifty-five $75(83.3 \%)$ males \& five $15(16.7 \%)$ females, the male to female ratio was 5:1 as shown in figure- 1 .

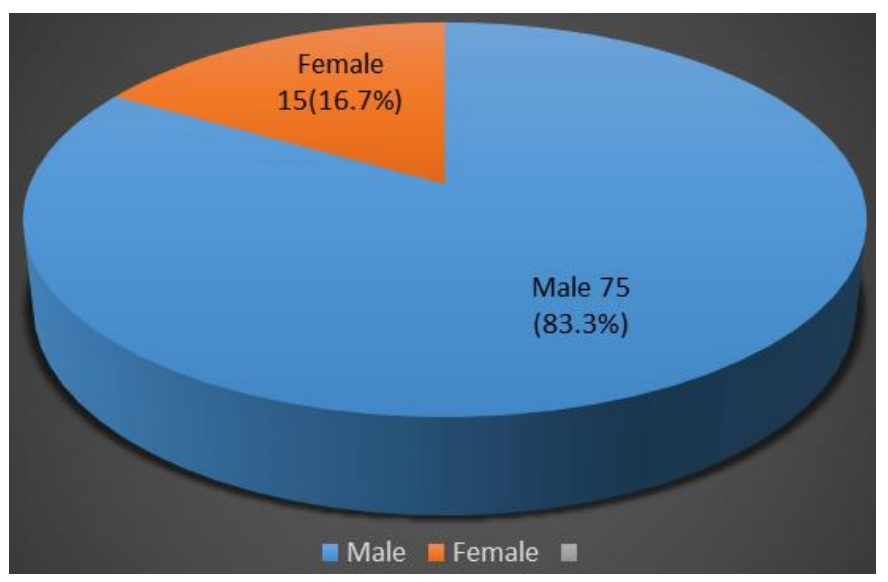

Fig 1: Distribution of patients according to their gender.

The study included (90) patients, their mean age \pm Standard deviation (SD) (43.15 \pm 9.7 years) and (45) apparently healthy subjects, their mean age \pm SD (43.07 \pm 9.20 years $)$ as shown in Table-1.

Table 1: Distribution of mean age with \pm standard deviation for patient and control groups.

\begin{tabular}{|c|c|c|}
\hline Group & Number & Mean \pm SD (year) \\
\hline Patients & 90 & $43.15 \pm 9.7$ \\
\hline Controls & 45 & $43.07 \pm 9.20$ \\
\hline
\end{tabular}

The mean BASDAI level of patients treated with conventional treatment $(4.45 \pm 2.23)$ higher than patients on biological treatment (infliximab infusion) $(2.70 \pm 0.96)$ and this difference is statistically significant $(\mathrm{P}-$ Value $=0.005)$ as shown in Table-2.

Table 2: Mean Bath Ankylosing Spondylitis Disease Activity Index (BASDAI) with \pm standard deviation for patient according to type of treatment.

\begin{tabular}{|c|c|c|c|}
\hline \multicolumn{3}{|c|}{ Group } \\
\hline \multicolumn{3}{|c|}{ Patient biology } & \multicolumn{2}{c|}{ Patient conventional } \\
\hline Mean & Standard deviation & Mean & Standard deviation \\
\hline 2.70 & 0.96 & 4.45 & 2.23 \\
\hline \multicolumn{3}{|c|}{ P-Value $=<0.001$ Statistically significant } \\
\hline
\end{tabular}

The mean BASFI level of patients treated with conventional treatment $(4.80 \pm 2.18)$ higher than patients on biological treatment (infliximab infusion) (3.44 \pm 1.05$)$ and this difference is statistically significant $(\mathrm{P}-$ Value $=<0.001)$ as shown in Table-3.

Table 3: Mean Bath Ankylosing Spondylitis Functional Index (BASFI) with \pm standard deviation for patients according to type of treatment.

\begin{tabular}{|c|c|c|c|}
\hline \multicolumn{4}{|c|}{ Group } \\
\hline \multicolumn{3}{|c|}{ Patient biology } & \multicolumn{2}{c|}{ Patient conventional } \\
\hline Mean & Standard deviation & Mean & Standard deviation \\
\hline 3.44 & 1.05 & 4.80 & 2.18 \\
\hline \multicolumn{3}{|c|}{ P-Value $=<0.001$ Statistically significant } \\
\hline
\end{tabular}

Mean serum level of hs- CRP (mg/L) higher in patients treated with conventional treatment, than in patients on biological treatment (infliximab infusion) and this difference is statistically significant $(\mathrm{P}$-value $=0.013)$ as shown in Table-4.

Table 4: Serum levels of hs- CRP (mg/L) in patients group according to type of treatment.

\begin{tabular}{|c|c|c|}
\hline Group & $\begin{array}{c}\text { Conventional } \\
\text { Treatment }\end{array}$ & $\begin{array}{c}\text { Biological treatment } \\
\text { (Infliximab) }\end{array}$ \\
\hline Number & 45 & 45 \\
\hline Mean $(\mathrm{mg} / \mathrm{L})$ & 16.16 & 10.51 \\
\hline Standard deviation & \pm 12.40 & $8.41 \pm$ \\
\hline \multicolumn{2}{|c|}{ P-value $=0.013$ Statistically significant } \\
\hline
\end{tabular}

Mean level of ESR $(\mathrm{mm} / 1 \mathrm{hr})$ higher in patients treated with conventional treatment, than in patients on biological treatment (infliximab infusion) and this difference is not statistically significant $(\mathrm{P}$ - value $=0.3051)$ as shown in Table5 .

Table 5: ESR levels $(\mathrm{mm} / \mathrm{hr})$ in-patient group according to type of treatment.

\begin{tabular}{|c|c|c|}
\hline Group & $\begin{array}{c}\text { Conventional } \\
\text { treatment }\end{array}$ & $\begin{array}{c}\text { Biological treatment } \\
\text { (Infliximab) }\end{array}$ \\
\hline Number & 45 & 45 \\
\hline Mean (mm/1hr) & 27.60 & 22.07 \\
\hline Standard deviation & \pm 22.84 & $18.35 \pm$ \\
\hline \multicolumn{2}{|r|}{ P-value $=0.3051$ Not statistically significant } \\
\hline
\end{tabular}

\section{Discussion}

Ankylosing spondylitis (AS) is a potentially disabling chronic inflammatory condition affecting the axial skeleton that is manifested by chronic back pain. The onset is typically before 45 years of age ${ }^{[7]}$.

Regarding the gender variation in the susceptibility to AS patients reported by the present study which showed that the 
disease is more predominant in males than in females with a ratio of 11:1, this result nearly in agreement with local study done by Rawaa et al. who found that male to female ratio 14:1 ${ }^{[8]}$ which disagrees with chen et al. who showed male: female ratio 3:1 ${ }^{[9]}$ and this inconsistency might be attributed to low sample size of the present study.

Ankylosing spondylitis is a disease which occurs during the third decade of life ${ }^{[10]}$, rarely at the age older than 45 year. About $10-20 \%$ of patients have the disease between 10 and 20 year of age ${ }^{[11]}$. The mean age of the patients with AS in this study was $43.15 \pm 9.7$ years as shown in [Table-1],

This result was more than that in previous study done on Iraqi AS patients by Rawaa et al. that reported mean age of AS patient of $37.1 \pm 8.9$ years ${ }^{[10]}$, and other international study of Demirdal et al. in AS Turkish patients that reported mean age of participated AS patient of 37.9 \pm 12.7 years ${ }^{[12]}$.

In this study, we analyzed the correlation between BASDAI, BASFI and type of treatment between two patient groups, one of them on conventional treatment and other treated with infliximab infusion (anti-TNF agent), and the results showed that BASDAI and BASFI level of patients treated with conventional treatment was higher than patients on biological treatment (infliximab infusion) and results suggested that correlation after biological treatment, with the reduction of disease activity, physical function also improved. Decreased value in BASDAI and BASFI score also showed a clear correlation, indicating that these two questionnaires could act as good evaluation tools for therapeutic effect of infliximab.

This result in agreement with study done on Chinese ankylosing spondylitis patients by Zhiming Lin et al. who found that BASDAI and BASFI in AS patients decreased significantly after Etanercept or infliximab treatment ${ }^{[13]}$.

Studies have shown that TNF inhibitors improve healthrelated quality of life, patient-reported outcomes, anemia, Creactive protein (CRP) levels, and sleep quality in patients with AS because TNF inhibitors control inflammation in the spine, as measured by various MRI sequences ${ }^{[14]}$.

In the current study we found that mean serum level of hsCRP higher in patients treated with conventional treatment, than in patients on biological treatment (infliximab infusion) and this difference is statistically significant $(\mathrm{P}$-value = 0.0235 ) and these results were in accordance with other study done by Turina et al. who found that hs-CRP is a useful biomarker of inflammation in this context as, despite not being elevated in all patients at baseline, it rapidly and significantly decrease in both axial and peripheral SpA treated with either infliximab or etanercept ${ }^{[15]}$.

In the current study we found that mean level of ESR higher in patients treated with conventional treatment, than in patients on biological treatment (infliximab infusion) and this difference is not statistically significant $(\mathrm{P}$-value $=0.3051)$ which disagrees with Luc et al., that is found that there was a strong association between ESR level at baseline and clinical response to treatment with anti-TNF after 3 months, supporting a potential distinctive exploitation of ESR in identifying AS patients suitable for treatment with anti-TNF, which is also of particular relevance in light of the costs of biologics and the side effects of these drugs and this disagreement due to difference in sample size and difference in study population ${ }^{[16]}$.

\section{Acknowledgement}

The authors are grateful to authorities of Baghdad Teaching Hospital, Department of Medicine/Unit of Rheumatology.
No conflicts of interest: Self-funding source

Ethical clearance: From the Ministry of health and Environment/ scientific committee

\section{References}

1. Braun J, Sieper J. Ankylosing spondylitis. The Lancet. 2007; 369(9570):1379-90.

2. Schett G, Landewé R, van der Heijde D. Tumour necrosis factor blockers and structural remodelling in ankylosing spondylitis: what is reality and what is fiction? Ann Rheum Dis. 2007; 66:709.

3. Song IH, Poddubnyy DA, Rudwaleit M, Sieper J. Benefits and risks of ankylosing spondylitis treatment with nonsteroidal antiinflammatory drugs. Arthritis \& rheumatism. 2008; 58(4):929-38.

4. Kruithof E, Baeten D, Van den Bosch F, Mielants H, Veys EM, De Keyser F. Histological evidence that infliximab treatment leads to downregulation of inflammation and tissue remodelling of the synovial membrane in spondyloarthropathy. Annals of the rheumatic diseases. 2005; 64(4):529-36.

5. Rostom S, Benbouaaza K, Amine B, Bahiri R, Yacoub YI, Alla SA et al. Psychometric evaluation of the Moroccan version of the Bath Ankylosing Spondylitis Functional Index (BASFI) and Bath Ankylosing Spondylitis Disease Activity Index (BASDAI) for use in patients with ankylosing spondylitis. Clinical rheumatology. 2010; 29(7):781-8.

6. Navarro-Compán V, Van Der Heijde D, Combe B, Cosson C, Van Gaalen FA. Value of high-sensitivity Creactive protein for classification of early axial spondyloarthritis: results from the DESIR cohort. Annals of the rheumatic diseases. 2013; 72(5):785-6.

7. Sieper J, Rudwaleit M, Baraliakos X, Brandt J, Braun J, Burgos-Vargas R. The Assessment of Spondylo Arthritis international Society (ASAS) handbook: a guide to assess spondyloarthritis. Annals of the rheumatic diseases. 2009; 68(2):ii1-44.

8. Alosami MH, Khalid AlObaidi E, Al-Qorashi RM. Lipid profile in a sample of Iraqi Patients with Ankylosing Spondylitis treated with TNF alpha inhibitor (Infliximab), 2015.

9. Chen HH, Chen TJ, Chen YM, Ying-Ming C, Chen DY. Gender differences in ankylosing spondylitis-associated cumulative healthcare utilization: a population-based cohort study. Clinics. 2011; 66(2):251-4.

10. Sieper J, Conaghan PG, Denton C, Foster H. Anklosing spondylitis. Oxford textbook of rheumatology. 4th ed. United Kingdom: oxford university press, 2013, 879-89.

11. Rudwaleit M, Claudepierre P, Wordsworth P, Cortina EL, Sieper J, Kron M. Effectiveness, safety, and predictors of good clinical response in 1250 patients treated with adalimumab for active ankylosing spondylitis. The Journal of rheumatology. 2009; 36(4):801-8.

12. Demirdal SE, Cakir T, Tugrul TU, Subasi V. Coexisting of fibromyalgia syndrome and ankylosing spondylitis. Acta Medica Mediterranea. 2013; 29:827.

13. Lin Z, Bei JX, Shen M. A genome-wide association study in Han Chinese identifies new susceptibility loci for ankylosing spondylitis. Nat Genet. 2012; 44:73.

14. Best JM. Rubella. InSeminars in fetal and neonatal medicine. 2007; 12(3):182-92

15. Turina MC, Yeremenko N, Paramarta JE, De Rycke L, Baeten D. OP0297 Calprotectin (S100A8/9) as Serum 
Biomarker for Clinical Response in Proof-Of-Concept Trials in Axial and Peripheral Spondyloarthritis. Annals of the Rheumatic Diseases. 2014; 73(Suppl 2):174.

16. Luc M, Gossec L, Ruyssen-Witrand A, Salliot C, Duclos M, Guignard S, Dougados M. C-reactive protein predicts tumor necrosis factor-alpha blocker retention rate in axial ankylosing spondylitis. The Journal of rheumatology. 2007; 34(10):2078-81. 